University of Wollongong

Research Online

Faculty of Engineering and Information

Faculty of Engineering and Information

Sciences - Papers: Part A

Sciences

$1-1-2014$

\title{
Analysis of subsynchronous torsional interaction of HVDC system integrated hydro units with small generator-to-turbine inertia ratios
}

Yin Chin Choo

University of Wollongong, ycc260@uowmail.edu.au

Ashish Agalgaonkar

University of Wollongong, ashish@uow.edu.au

Kashem M. Muttaqi

University of Wollongong, kashem@uow.edu.au

Sarath Perera

University of Wollongong, sarath@uow.edu.au

Michael Negnevitsky

University of Tasmania, michael.negnevitsky@utas.edu.au

Follow this and additional works at: https://ro.uow.edu.au/eispapers

Part of the Engineering Commons, and the Science and Technology Studies Commons

Research Online is the open access institutional repository for the University of Wollongong. For further information contact the UOW Library: research-pubs@uow.edu.au 


\title{
Analysis of subsynchronous torsional interaction of HVDC system integrated hydro units with small generator-to-turbine inertia ratios
}

\author{
Abstract \\ The constant current controllers at high voltage direct current (HVDC) rectifier stations and the outer \\ loops which set the reference to the current controller have potential to introduce negative damping on \\ the nearby generating units. It is therefore vital to investigate the torsional interaction behavior between \\ turbine-generator (TG) units and the HVDC systems over a frequency range of interest. In this paper, \\ subsynchronous torsional interaction (SSTI) phenomenon for hydroelectric TG units with small generator- \\ to-turbine inertia (GTI) ratios interconnected to an HVDC system has been investigated. The sensitivity of \\ different system parameters, such as generating capacity and loading, DC power flow, AC network \\ strength and current controller gains, towards electrical damping contribution is also examined. Hydro \\ units with different shaft systems are examined for SSTI proneness by conducting perturbation analysis. \\ The impact of hydroelectric TG units with different GTI ratios has also been examined by applying a three- \\ phase to ground fault at the rectifier station. Simulation studies have been carried out in PSCAD \\ §/EMTDC ( $)$ environment. Due to lack of modal damping with relatively low decrement factor and \\ logarithmic decrement, sustained and growing TG torque oscillations are noted for certain operating \\ conditions of hydro units with small GTI ratios interconnected with an HVDC system..
}

\section{Keywords}

hvdc, units, interaction, torsional, small, subsynchronous, analysis, generator, turbine, inertia, ratios, hydro, integrated, system

\section{Disciplines \\ Engineering | Science and Technology Studies}

\section{Publication Details}

Y. Choo, A. P. Agalgaonkar, K. M. Muttaqi, S. Perera \& M. Negnevitsky, "Analysis of subsynchronous torsional interaction of HVDC system integrated hydro units with small generator-to-turbine inertia ratios," IEEE Transactions on Power Systems, vol. 29, (3) pp. 1064-1076, 2014. 


\title{
Analysis of Subsynchronous Torsional Interaction of HVDC System Integrated Hydro Units with Small Generator-to-Turbine Inertia Ratios
}

\author{
Y. C. Choo, A. P. Agalgaonkar, Senior Member, IEEE, K. M. Muttaqi, Senior Member, IEEE, \\ S. Perera, Senior Member, IEEE, and M. Negnevitsky, Senior Member, IEEE
}

\begin{abstract}
The constant current controllers at high voltage direct current (HVDC) rectifier stations and the outer loops which set the reference to the current controller have potential to introduce negative damping on the nearby generating units. It is therefore vital to investigate the torsional interaction behavior between turbine-generator (TG) units and the HVDC systems over a frequency range of interest. In this paper, subsynchronous torsional interaction (SSTI) phenomenon for hydroelectric TG units with small generator-to-turbine inertia (GTI) ratios interconnected to an HVDC system has been investigated. The sensitivity of different system parameters, such as generating capacity and loading, DC power flow, AC network strength and current controller gains, towards electrical damping contribution is also examined. Hydro units with different shaft systems are examined for SSTI proneness by conducting perturbation analysis. The impact of hydroelectric TG units with different GTI ratios has also been examined by applying a three-phase to ground fault at the rectifier station. Simulation studies have been carried out in PSCAD ${ }^{\circledR} /$ EMTDC $^{(\mathcal{C}}$ environment. Due to lack of modal damping with relatively low decrement factor and logarithmic decrement, sustained and growing TG torque oscillations are noted for certain operating conditions of hydro units with small GTI ratios interconnected with an HVDC system.
\end{abstract}

Index Terms-Hydroelectric turbine-generator, high voltage direct current (HVDC), subsynchronous torsional interaction (SSTI), damping torque analysis, perturbation analysis.

\section{INTRODUCTION}

$\mathbf{S}$ UBSYNCHRONOUS torsional interaction (SSTI) between a steam turbine-generator (TG) unit and an highvoltage direct current (HVDC) system received deliberate attention especially after the field tests at Square Butte, North Dakota, USA revealed the undesirable interactions between the HVDC terminal and an electrically-close TG unit [1]. The increasing complexity of the electrical network as well as the stressed system conditions under various contingencies demand dynamic interaction studies from stability perspective.

To date, various research aspects associated with SSTI behavior of turbogenerators have been reported in the literature. However, limited number of research studies have

This work is supported by the Australian Research Council under ARC Discovery Grant, "Optimizing Control of Hydroelectric Turbines Subject to Basslink Instability".

Y. C. Choo, A. P. Agalgaonkar, K. M. Muttaqi and S. Perera are with the University of Wollongong, NSW 2522, AUSTRALIA (e-mail: YinChin.Choo@transgrid.com.au; ashish@uow.edu.au; kashem@uow.edu.au; sarath@uow.edu.au).

M. Negnevitsky is with the University of Tasmania, Hobart 7005, AUSTRALIA (e-mail: Michael.Negnevitsky@utas.edu.au). been conducted for hydroelectric TG units, especially in the close vicinity of HVDC systems, due to the fact that the high inherent generator-to-turbine inertia (GTI) ratios of hydro units enhance the modal damping at torsional frequencies, thereby minimizing the risk of sustained torsional oscillations [2]. Unlike Francis and Pelton wheels, Kaplan units could be more prone to SSTI due to their torsional frequencies within the negative damping frequency range of normal DC operation [3]. Authors of [3] have also indicated that the hydroelectric TG units with a low GTI ratio may be susceptible to SSTI problem. However, thorough investigations for different system conditions are required to depict the realistic behavior of hydroelectric TG units connected to HVDC systems. Moreover, it is very important to investigate the hydroelectric TG response for network side perturbations and the effect of negative damping posed by an HVDC current controller and the outer loops which set the reference to the current controller. This is because there could be certain network conditions such as close association of an HVDC system with a hydroelectric unit with small GTI ratio, wherein the negative damping introduced by the HVDC current controller and the outer loops which set the reference to the current controller may trigger sustained torsional oscillations on the shaft of the machine [3].

The complex torque coefficients method has been proposed in [4], [5] for SSTI analysis of TG sets. The interaction phenomenon for the electrical and the mechanical systems has been explained in [4] while the applicability of the proposed approach on a test network is presented in [5]. Complex torque analysis computes the change in electromagnetic torque in terms of synchronizing and damping torque components [4], [6]. It facilitates the formulation of state-space model and transfer function representation of each power system component [6]. The system stability can be assured if the electrical damping is positive for the requisite frequency range of interest. The proof of the positive-net-damping stability criterion has been presented in [7] using the Nyquist criterion. The clarification has also been made in [7] that the net damping should be assessed for the open-loop resonances, as well as for low frequencies where the loop gain goes beyond unity.

The multi-infeed HVDC interactions have been analyzed in [8] using small-signal analysis and verified with the aid of PSCAD ${ }^{\circledR} /$ EMTDC $^{\complement}$. The application of frequency-domain analysis for investigating SSTI between synchronous machine 
and a current-controlled voltage source converter (VSC) has been demonstrated in [6]. The subsynchronous resonance characteristic of the VSC-based HVDC using damping torque analysis, eigenvalue analysis, and transient simulation studies has been investigated in [9]. The performance indices to assess torsional damping and system susceptibility to experience torsional oscillations have been presented in [10]. The evaluation and enhancement of small signal stability of a renewableenergy-based electricity distribution system have been detailed in [11] while hydrokinetic-energy-conversion systems, which consists of a number of cascaded stages, are studied in [12], [13]. The development of high performance control systems for an HVDC converter connected to a weak AC network is described in [14].

A sustained subsynchronous power oscillation, however, was observed within the normal frequency range of hydropower unit torsional modes during a startup test of an electrical island in the Nordic power system although hydroelectric units are not known to be relatively susceptible to SSTI [15]. It was noted that self-excitation may happen due to the induction generator effect regardless of the inertia ratio and the mechanical damping if the electrical network size is small. This stability criterion is governed by the total effective resistance of the electrical system at the resonance frequency. Turbine damping and the inertia ratio are the most vital factors which decide the stability condition close to the stability boundary [15].

This paper aims to investigate SSTI phenomenon for HVDC system integrated hydro units under different system conditions. Damping torque analysis has been carried out to determine the degree of sensitivity of system parameters, such as hydroelectric unit with different power output capacities and loading levels, varying power flows through a DC link, different levels of AC system strength and current controller gains towards electrical damping contribution. Perturbation analysis is conducted to assess the dynamic response of a hydroelectric unit with different GTI ratios.

The paper is structured as follows. Section II describes the system model. Section III describes the modal analysis of a hydroelectric TG unit. Section IV outlines the effect of HVDC constant current controller on electrical damping and illustrates the methodology to investigate system stability. The hydroelectric unit integrated to CIGRE first HVDC benchmark system has been used as a test case and presented in Section V. Simulation results are presented in Section VI. The paper is concluded in Section VII.

\section{SySTEM MOdEL}

For representing the system model involving generator, HVDC system and AC system, the dynamic characteristics of the power system, described by a set of first order non-linear differential-algebraic equations, are linearized at an equilibrium point [16]. The overall system dynamics are represented in the synchronously rotating $d q$ reference frame fixed in the rotor.

\section{A. Linearized Synchronous Machine Model}

A three-phase salient pole synchronous machine is modeled in detail to represent the hydroelectric TG unit. The equivalent circuits of $d q$-axes are shown in Figs. 1(a) and (b) respectively. The rotor of a hydroelectric unit normally comprises of a field winding and an armortisseur (damper) winding on the direct axis and a damper winding on the quadrature axis. The linearized machine model has the following state-space representation [16], [17]:

$$
\left[\begin{array}{c}
\Delta \dot{\psi}_{d} \\
\Delta \dot{\psi}_{q} \\
\Delta \dot{\psi}_{f d} \\
\Delta \dot{\psi}_{k d} \\
\Delta \dot{\psi}_{k_{q}} \\
\Delta \dot{\omega}_{r} \\
\Delta \dot{\dot{\delta}}_{r}
\end{array}\right]=\left[A_{s m}\right]\left[\begin{array}{c}
\Delta \psi_{d} \\
\Delta \psi_{q} \\
\Delta \psi_{f d} \\
\Delta \psi_{k d} \\
\Delta \psi_{k q} \\
\Delta \omega_{r} \\
\Delta \dot{\delta}_{r}
\end{array}\right]+\left[B_{s m}\right]\left[\begin{array}{c}
\Delta v_{d}^{e} \\
\Delta v_{q}^{e} \\
\Delta v_{f d}^{\prime r} \\
\Delta v_{k d}^{\prime r} \\
\Delta v_{k q}^{\prime r}
\end{array}\right]
$$

where, the state vector of the synchronous machine comprises of state variables $d$ - and $q$ - axes stator flux linkages per second $\left(\psi_{d}\right.$ and $\left.\psi_{q}\right)$, rotor flux linkages per second for a field winding $\left(\psi_{f d}\right)$ and for $d$ - and $q$ - axes damper windings $\left(\psi_{k d}\right.$ and $\left.\psi_{k q}\right)$, rotor speed $\left(\omega_{r}\right)$, nominal frequency $\left(\omega_{s}\right)$ and rotor angle $\left(\delta_{r}\right)$. The input vector comprises of $d$ - and $q$ - axes voltage referred to the synchronous rotating reference frame $\left(v_{d}^{e}\right.$ and $\left.v_{q}^{e}\right)$ and voltages referred to a reference frame fixed in the rotor $\left(v_{f d}^{\prime r}\right.$, $v_{k d}^{\prime r}$ and $\left.v_{k q}^{\prime r}\right) . A_{s m}$ is the state matrix and $B_{s m}$ is the input matrix.

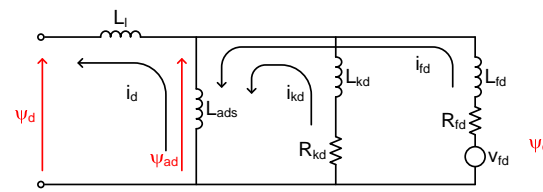

(a)

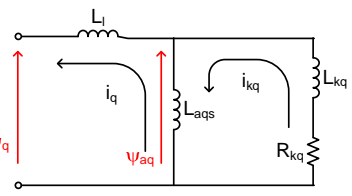

(b)
Fig. 1. Equivalent circuits of $d q$-axes for synchronous machine

\section{B. Linearized HVDC System}

The T-model of an HVDC system, as shown in Fig. 2, has a linearized, state-space formulation as follows:

$$
\begin{aligned}
{\left[\begin{array}{c}
\Delta \dot{I}_{d r} \\
\Delta \dot{I}_{d i} \\
\Delta \dot{V}_{d m}
\end{array}\right]=} & {\left[\begin{array}{ccc}
-\frac{R_{d}}{L_{d}} & 0 & -\frac{1}{L_{d}} \\
0 & -\frac{R_{d}}{L_{d}} & \frac{1}{L_{d}} \\
\frac{1}{C_{d}} & -\frac{1}{C_{d}} & 0
\end{array}\right]\left[\begin{array}{c}
\Delta I_{d r} \\
\Delta I_{d i} \\
\Delta V_{d m}
\end{array}\right] } \\
& +\left[\begin{array}{cc}
\frac{1}{L_{d}} & 0 \\
0 & -\frac{1}{L_{d}} \\
0 & 0
\end{array}\right]\left[\begin{array}{c}
\Delta V_{d r} \\
\Delta V_{d i}
\end{array}\right]
\end{aligned}
$$

where, the three state variables are the dc-side currents at rectifier and inverter stations $\left(I_{d r}\right.$ and $\left.I_{d i}\right)$ and the capacitor voltage at the middle point of the DC transmission line $\left(V_{d m}\right)$. The two inputs are the direct voltages at rectifier and inverter stations $\left(V_{d r}\right.$ and $V_{d i}$ ) respectively.

The direct voltage and current can be manipulated by controlling the internal voltages $\left(V_{d 0 r} \cos \alpha\right.$ and $\left.V_{d 0 i} \cos \gamma\right)$. $V_{d 0 r}$ and $V_{d 0 i}$ refer to the ideal no-load direct voltages at rectifier and inverter stations respectively, $\alpha$ is the ignition delay angle and $\gamma$ is the extinction advance angle [16]. 


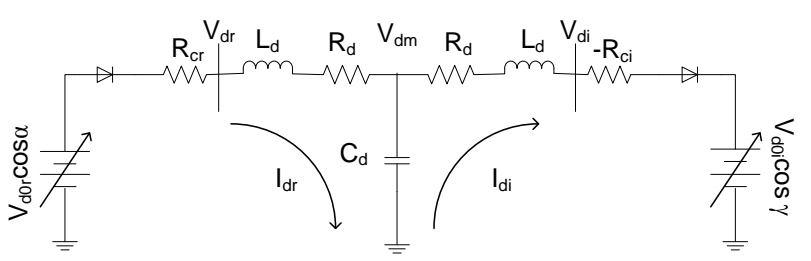

Fig. 2. HVDC T-Model Transmission Line

\section{Linearized AC Electrical Network}

An electrical network comprises of an impedance connected in series with the generator $\left(Z_{S M}\right)$, an ac system connected in parallel to the generator $\left(Z_{\text {sys }}\right)$ and filter impedance $\left(Z_{\text {filter }}\right)$.

The impedances, in general, have the following representation in the $d q$-reference frame [17]:

$$
Z=\left[\begin{array}{cc}
R+s L & -\omega_{s} L \\
\omega_{s} L & R+s L
\end{array}\right]
$$

where, $R$ is the resistance and $L$ is the inductance.

Accordingly, the $d q$ component of voltage can be expressed as:

$$
\Delta V_{d q}=\left[Z_{S M}+\left(Z_{\text {sys }}^{-1}+Z_{\text {filter }}^{-1}\right)^{-1}\right] \Delta I_{d q}
$$

\section{Interface between $A C$ and DC Systems}

The linearized state-space model for each subsystem has been represented individually as shown in Subsections II-A, II-B and II-C. The linearized representation of the ac-dc interaction equations derived from the power balance equation, as in (5), highlights the small-signal inter-relationship between ac and de systems as shown below:

$$
\left[\begin{array}{l}
\Delta i_{a c r} \\
\Delta \phi_{a c r}
\end{array}\right]=\left[\begin{array}{ccc}
0 & 0 & \frac{\sqrt{6}}{\pi} B_{r} T_{r} \\
x_{a c d c 1} & \frac{\sin \alpha_{0}}{\sin \phi_{a c r 0}} & x_{a c d c 2}
\end{array}\right]\left[\begin{array}{c}
\Delta v_{a c r} \\
\Delta \alpha \\
\Delta I_{d r}
\end{array}\right]
$$

where, $\quad x_{a c d c 1}=-\frac{X_{c r} I_{d r 0}}{\sqrt{2} T_{r} v_{a c r 0}^{2} \sin \phi_{a c r 0}}$ and $x_{a c d c 2}=$ $\frac{X_{c r}}{\sqrt{2} T_{r} v_{a c r 0} \sin \phi_{a c r} 0}, i_{a c}=$ RMS value of the alternating current at fundamental frequency, $\phi_{a c}=$ phase angle between fundamental line current and the line-to-neutral source voltage, $v_{a c}=$ line-to-line voltage of an ac system, $B=$ number of bridges in series, $T=$ transformer ratio, $X_{c}=$ commutating reactance, subscript $r$ represents the rectifier-side and subscript 0 denotes the initial operating condition.

Since each subsystem has been represented in a different reference frame, all the variables need to be transformed into common reference frame before the integration of different subsystems.

\section{Modal Analysis of a Hydroelectric TURBINE-GENERATOR UNIT}

The mechanical shaft system of a hydroelectric TG unit typically consists of three rotor masses, which are turbine, generator and exciter. It can be represented as a lumped mass-spring-damper system. The torsional oscillations can be mathematically represented by the equation of motion [18]:

$$
2 H \ddot{\theta}+D \dot{\theta}+K \theta=T
$$

where $H$ is the diagonal matrix of inertia constant for all three masses, $D$ and $K$ are tridiagonal symmetric matrices of damping coefficient and spring stiffness respectively. $\theta$ is the vector of rotor angle whilst $T$ is the vector of the externally applied torque.

Modal analysis can be performed on the system represented by (6) with the substitution of $\theta=Q \theta_{m}$ as modal angle transformation and premultiplication of $Q^{t}$, where $Q$ is the transformation matrix, $Q^{t}$ is the transpose of $Q$ and $\theta_{m}$ is the modal angle [18].

$$
2 Q^{t} H Q \ddot{\theta}_{m}+Q^{t} D Q \dot{\theta}_{m}+Q^{t} K Q \theta_{m}=Q^{t} T
$$

Equation (7) can be rewritten as follows:

$$
2 H_{m} \ddot{\theta}_{m}+D_{m} \dot{\theta}_{m}+K_{m} \theta_{m}=Q^{t} T
$$

where $H_{m}, D_{m}$ and $K_{m}$ denote the modal inertia, damping coefficient and shaft stiffness matrices respectively. Equation (8) is in decoupled form, wherein $H_{m}, D_{m}$ and $K_{m}$ matrices are in diagonal form with the proper selection of $Q$.

Consider a two-mass hydroelectric unit with turbine and generator rotor. The modal inertia $\left(H_{m}\right)$, modal damping coefficient $\left(D_{m}\right)$, decrement factor $\left(\sigma_{m}\right)$ and logarithmic decrement $\left(\delta_{m}\right)$ for the torsional mode $\left(f_{n}\right)$ of the modal system can be represented as follows [3], [18]:

$$
\begin{aligned}
H_{m} & =G T I\left(H_{t u r}+H_{\text {gen }}\right) \\
D_{m} & =G T I^{2} D_{\text {tur }}+D_{t g}(G T I+1)^{2} \\
\sigma_{m} & =\frac{D_{m}}{4 H_{m}} \\
\delta_{m} & =\frac{\sigma_{m}}{f_{n}}
\end{aligned}
$$

where GTI is the generator-to-turbine inertia ratio and the subscripts 'gen' and 'tur' refer to generator and turbine respectively, and ' $t g$ ' refers to turbine-generator.

For a high GTI ratio, the modal inertia of the shaft system is large as indicated by (9). This large modal inertia subsequently reduces the decrement factor of the electrical damping $\left(\sigma_{e}\right)$, which is described as follows [9]:

$$
\sigma_{e}=\frac{D_{e}}{4 H_{m}}
$$

where $D_{e}$ is the electrical damping coefficient.

The inherent mechanical modal torsional damping may become adequate to counteract the effect of negative damping posed by HVDC current-controller. A thorough investigation of this particular aspect has been conducted in this paper for a hydroelectric generator connected to an HVDC system.

Torsional interactions are principally a transient torque phenomenon, and they arise as a result of normal switching operations and faults. Significant torque oscillations at torsional frequencies are caused by a switching incident on the transmission system [19]. If the complement of the system resonance frequency is close to the mechanical torsional mode frequency and the combined electro-mechanical system lacks in system damping, then it may result in sustained or growing torsional oscillations in torque and subsequently result in instability [20]. 
System SSTI stability can be determined by system modal decrement factor or logarithmic decrement as indicated by (11) and (12). The pictorial representation of the decrement factor is shown in Fig. 3 for a variation of turbine damping $\left(D_{t u r}\right)$ and generator-to-turbine inertia ratio. The hydroelectric unit may experience SSTI instability with sustained or growing torque oscillations for any combination of $D_{\text {tur }}$ and the GTI ratio that falls below the stability boundary as shown in Fig. 3. The decrement factor plot also depends on $D_{t g}$ as seen in (10), and for a higher $D_{t g}$, the system modal damping will be greatly improved. Accordingly, a wide range of turbinegenerator damping has also been accounted in this paper to analyze its impact on modal damping.

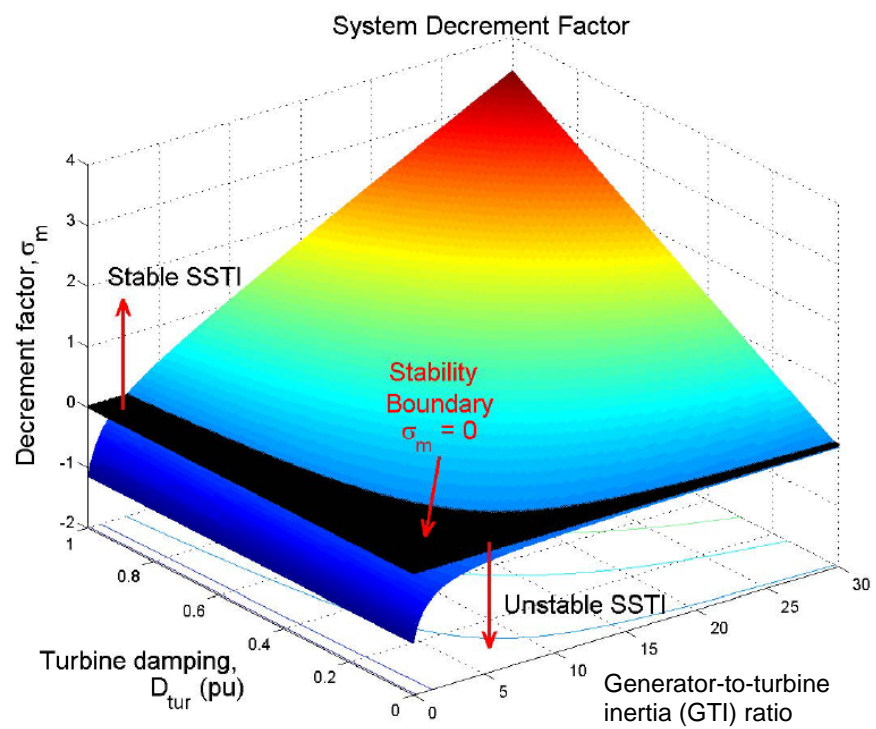

Fig. 3. System modal decrement factor in determining SSTI stability

\section{EFFECT OF HVDC CONSTANT CURRENT CONTROLlER ON ELECTRICAL DAMPING}

This section discusses the effect of HVDC current controller on electrical damping for a hydro machine connected to an HVDC system. It is assumed that the commutating voltage and phase angle at the rectifier station of an HVDC system are strongly dependent on the generator internal bus [18].

Consider that the generator rotor is oscillating sinusoidally at a constant speed of $\omega_{s}$ :

$$
\omega_{r}=\omega_{s}+m \sin \left(\omega_{m} t\right)
$$

where, $\omega_{r}$ is the rotor speed in $\mathrm{rad} / \mathrm{sec}, \omega_{s}$ is the nominal frequency in $\mathrm{rad} / \mathrm{sec}, m$ is the magnitude of the speed deviation, $\omega_{m}$ is the frequency of oscillation of the rotor speed in $\mathrm{rad} / \mathrm{sec}$, and $t$ is the time in sec.

With the changes in internal flux linkages neglected, the voltage induced in the armature of a generator is composed of three components, which are (i) nominal frequency $\left(\omega_{s}\right)$, (ii) subsynchronous frequency $\left(\omega_{s}-\omega_{m}\right)$, and (iii) supersyn- chronous frequency $\left(\omega_{s}+\omega_{m}\right)$ as seen in (15).

$$
\begin{aligned}
v_{a c}= & V_{p} \cos \left(\omega_{s} t\right)-\frac{m V_{p}}{2} \sin \left(\omega_{s}-\omega_{m}\right) t \\
& +\frac{m V_{p}}{2} \sin \left(\omega_{s}+\omega_{m}\right) t
\end{aligned}
$$

where $V_{p}$ is the amplitude of the fundamental ac voltage.

The HVDC system is considered to operate at normal conditions, i.e. the rectifier operates in constant current (CC) control mode and the inverter operates in constant extinction angle (CEA) control mode. Both CC and CEA controllers are based on proportional and integral (PI) logic to adjust the firing angle at rectifier and inverter stations respectively. The linearized PI controller operation at the rectifier station can be represented as follows:

$$
\Delta \alpha=\left(K_{p}+\frac{K_{i}}{s}\right) \Delta I_{d c}
$$

where, $\Delta$ represents small deviations, $\alpha$ is the rectifier firing angle, $K_{p}$ and $K_{i}$ are the proportional and integral gains respectively, $s$ is the Laplace transform variable and $I_{d c}$ is the dc-side current.

The linearized dc-side current of an HVDC system can be represented as follows [8], [21]:

$$
L_{d c} \frac{d \Delta i_{d c}}{d t}+R_{d c} \Delta i_{d c}=\Delta v_{d c}=\Delta v_{d c r}-\Delta v_{d c i}
$$

where, $i_{d c}$ is the dc-side current, $v_{d c r}$ and $v_{d c i}$ are the direct voltage at rectifier and inverter respectively. $L_{d c}$ is the DC line inductance and $R_{d c}$ is the DC line resistance.

Assuming that the system on the inverter side is a relatively strong system, its voltage is held approximately constant by CEA control, where $\Delta v_{d c i}=0$ (i.e. $\Delta v_{d c}$ will be equal to $\left.\Delta v_{d c r}\right)$. Thus, the HVDC load can be described in s-domain as follows:

$$
\Delta I_{d c}=Z_{h v d c}^{-1}(s) \Delta V_{d c}
$$

where $V_{d c}$ is the direct voltage and $Z_{h v d c}$ is the DC line impedance, which can be represented as $R_{d c}+s L_{d c}$.

The average direct voltage is represented as follows [8], [16]:

$$
V_{d c}=\frac{3 \sqrt{2}}{\pi} B_{r} T_{r} V_{a c r} \cos \alpha
$$

where, $B_{r}$ and $T_{r}$ are the number of bridges in series, and the transformer turns ratio at the rectifier station respectively, and $V_{a c r}$ is the line-to-line AC voltage.

Linearization of (19) yields the representation of the direct voltage with respect to the changes in rotor speed $\left(\Delta \omega_{r}\right)$ and rectifier firing angle $(\Delta \alpha)$ as follows:

$$
\Delta V_{d c}=\frac{3 \sqrt{2}}{\pi} B_{r} T_{r} V_{a c r 0}\left(\cos \alpha_{0} \Delta \omega_{r}-\sin \alpha_{0} \Delta \alpha\right)(20)
$$

where, $V_{a c r 0}$ is the initial AC voltage, $\alpha_{0}$ is the initial rectifier firing angle and $\Delta V_{a c r}=V_{a c r 0} \Delta \omega_{r}$.

Substituting (20) into (18), and by considering a PI type current controller operation at the rectifier station as described 
by (16), the dc-side current change can be expressed with respect to the change in rotor speed as follows:

$$
\frac{\Delta I_{d c}(s)}{\Delta \omega_{r}(s)}=\frac{Z_{h v d c}^{-1}(s) \frac{3 \sqrt{2}}{\pi} B_{r} T_{r} V_{a c r 0} \cos \alpha_{0}}{1+Z_{h v d c}^{-1}(s) \frac{3 \sqrt{2}}{\pi} B_{r} T_{r} V_{a c r 0} \sin \alpha_{0}\left(K_{p}+\frac{K_{i}}{s}\right)}
$$

The current flowing into $\mathrm{AC}$ system $\left(i_{a c}\right)$ is related to the dc-side current $\left(I_{d c}\right)$ by the following equation that expresses the AC-DC interaction [16], [18].

$$
i_{a c}=\frac{\sqrt{6}}{\pi} B_{r} T_{r} I_{d c} \cos \left(\omega_{s} t-\alpha\right)
$$

Linearization of (22) yields the small-signal inter-relationship between AC and DC systems of an HVDC system, as described below:

$$
\begin{aligned}
\Delta i_{a c}= & \frac{\sqrt{6}}{\pi} B_{r} T_{r} \cos \left(\omega_{s} t-\alpha\right) \Delta I_{d c} \\
& +\frac{\sqrt{6}}{\pi} B_{r} T_{r} I_{d c 0} \sin \left(\omega_{s} t-\alpha\right) \Delta \alpha
\end{aligned}
$$

where, $I_{d c 0}$ is the initial dc-side current.

The linearized ac-side current representation as in (23) can be rewritten as follows using (14) and (16):

$$
\begin{aligned}
\Delta i_{a c}= & \frac{\sqrt{6}}{\pi} B_{r} T_{r}\left|\frac{\Delta I_{d c}}{\Delta \omega_{r}}\left(\omega_{m}\right)\right| m\{\sin B \cos A \\
& \left.-\frac{K_{i} I_{d c 0}}{\omega_{m}} \sin A \cos B+K_{p} I_{d c 0} \sin A \sin B\right\}
\end{aligned}
$$

where, $A=\omega_{s} t-\alpha, B=\omega_{m} t+\phi$ and $\frac{\Delta I_{d c}}{\Delta \omega_{r}}\left(j \omega_{m}\right)=$ $\left|\frac{\Delta I_{d c}}{\Delta \omega_{r}}\left(\omega_{m}\right)\right| \angle \phi\left(\omega_{m}\right)$.

The representation of (24) in terms of the subsynchronous $\left(\omega_{\text {sub }}\right)$ and supersynchronous $\left(\omega_{\text {super }}\right)$ frequency components of the AC current can be illustrated as follows:

$$
\Delta i_{a c}=\frac{\sqrt{6}}{2 \pi} B_{r} T_{r}\left|\frac{\Delta I_{d c}}{\Delta \omega_{r}}\left(\omega_{m}\right)\right| m[x-y+z]
$$

where,

$$
\begin{aligned}
x & =\left(1-\frac{K_{i} I_{d c 0}}{\omega_{m}}\right) \sin \left(\omega_{\text {super }} t-\alpha+\phi\right), \\
y & =\left(1+\frac{K_{i} I_{d c 0}}{\omega_{m}}\right) \sin \left(\omega_{\text {sub }} t-\alpha-\phi\right), \\
z & =K_{p} I_{d c 0}\left[\cos \left(\omega_{\text {sub }} t-\alpha-\phi\right)-\cos \left(\omega_{\text {super }}-\alpha+\phi\right)\right] .
\end{aligned}
$$

The electromagnetic torque $\left(T_{e}\right)$ can be represented as:

$$
\Delta T_{e}=\frac{V_{a c r} \Delta i_{q}}{\omega_{r}}
$$

where $V_{a c r}$ is the commutating voltage at the rectifier bus and $i_{q}$ is the $q$-axis current. The electromagnetic power $\left(V_{a c r} \Delta i_{q}\right)$ is the power at synchronous speed. This electromagnetic power is equal to the electromagnetic torque with the assumption that $\omega_{r}=1.0 \mathrm{pu}$. It is thus obvious that the electromagnetic torque consists of sub- and super- synchronous frequency components.

A damping torque analysis is used in this paper to identify the contribution made by the network towards the electrical damping of the generator unit of interest. As discussed earlier, perturbation of the rotor speed will be reflected on the stator terminal voltage, causing the current to oscillate depending on the network impedance as seen from the generator perspective [22]. The sequence components of stator currents contain suband super- synchronous frequency components. This results in a change in electrical torque at a modulated frequency $\left(\omega_{m}\right)$.

The combined AC and HVDC system as seen in Fig. 4 is used to illustrate the damping torque analysis.

The electrical torque deviation can be obtained by disabling the rotor dynamics associated with the generator unit (i.e. neglecting the mechanical torque deviations) [6], [22], and applying a sinusoidal small speed perturbation $\left(\Delta \omega_{r}\right)$. The rotor speed to electrical torque transfer function $\left(G_{e}\right)$ can be computed by repeating this procedure for the frequency range of interest. The mathematical expression for $G_{e}$ can be given as:

$$
\frac{\Delta T_{e}}{\Delta \omega_{r}}(j \omega)=\left|G_{e}(\omega)\right| \angle \phi_{G e}(\omega)
$$

where, $\phi_{G e}$ is the relative phase angle.

The electrical damping can be plotted against the modulated frequency to depict the amount of electrical damping contribution from the electrical network, and thereby determining the system stability. The system is considered to be stable if the electrical damping is positive and associated phase angle lies between $+90^{\circ}$ and $-90^{\circ}$.

To calculate the electrical damping at the modulated frequency, the rotor speed and the electromagnetic torque signals are passed through a narrow-bandpass filter (with high quality factor) to extract the frequency components of interest. The 2nd-order mid-pass filter is used for extracting the related frequency component. The effective electrical damping $\left(D_{e}\right)$ and synchronizing coefficient $\left(S_{e}\right)$ can be calculated as follows [1], [22]:

$$
\begin{aligned}
D_{e}(\omega) & =\Re\left\{G_{e}(s)\right\}=\left|G_{e}(\omega)\right| \cos \phi_{G e} \\
S_{e}(\omega) & =\Im\left\{G_{e}(s)\right\}=\left|G_{e}(\omega)\right| \sin \phi_{G e}
\end{aligned}
$$

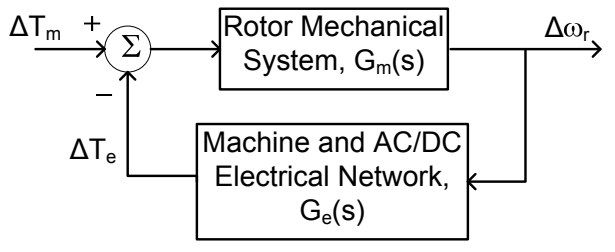

Fig. 4. Electrical and Mechanical Systems Diagram

\section{TEST CASE}

A hydroelectric turbine-generator unit connected to an HVDC system, with a parallel connection of an AC system is shown in Fig. 5. This is used as test case for damping torque analysis with a monopolar DC link rated at $500 \mathrm{kV}$, $1000 \mathrm{MW}$ connected to a hydroelectric unit. Hydroelectric units with rated capacities of 500 MVA, 840 MVA and 1000 MVA are considered for detailed investigation. The data for 500 MVA hydroelectric unit are obtained from [17]. The 840 MVA and 1000 MVA hydroelectric generators are represented by Sanxia generator data given in [23]. 
The HVDC system is represented by the CIGRE first HVDC benchmark model [24]. It is considered that the HVDC system operates with constant current (CC) control mode on the rectifier side and constant extinction angle (CEA) control mode on the inverter side as shown in Fig. 6. Accordingly, HVDC system can be represented as load, where the inverter side voltage is assumed to be constant. The dc-side current is kept constant by varying the firing angle $(\alpha)$ at the rectifier station. The rectifier controller mode will be changed to constant ignition angle (CIA) control mode if the minimum firing angle $\alpha_{\min }$ is hit, as no further direct voltage increment is allowed. For small signal analysis, it is assumed that the converter controllers are operating close to the normal operating conditions without changing the controller modes.

Both CC and CEA controllers are based on the PI logic to adjust the firing angle at the rectifier and inverter stations respectively. The difference between measured dc-side current and the current order is used as an input to the CC controller, whilst the difference between measured extinction angle and the extinction angle order is used as an input to the CEA controller as illustrated in Figs. 7(a) and 7(b) respectively.

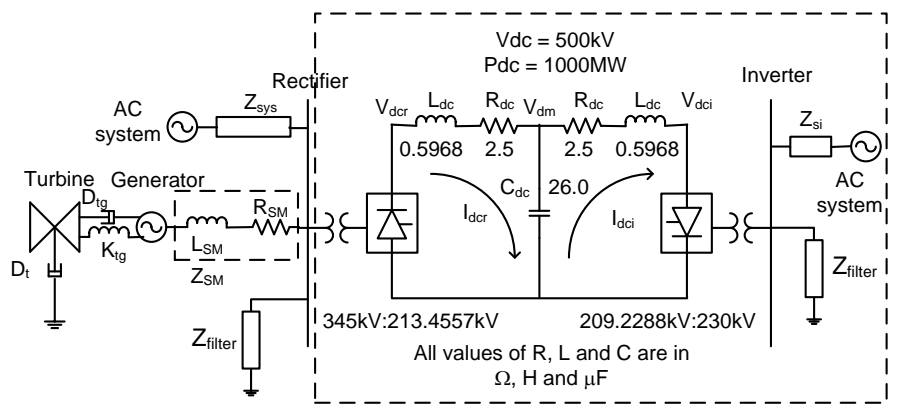

Fig. 5. Hydroelectric unit connected to an HVDC system

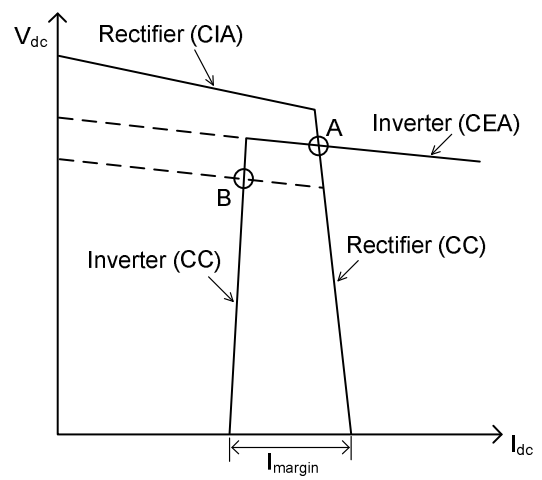

Fig. 6. Converter control steady state characteristics

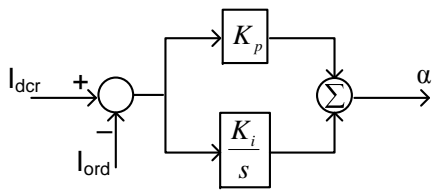

(a)

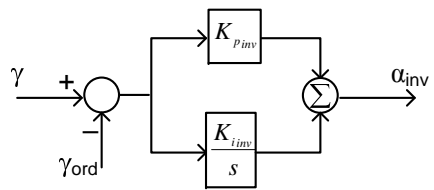

(b)
Fig. 7. HVDC control modes: (a) constant current controller at rectifier station (b) constant extinction angle controller at inverter station
The rest of the AC systems on the rectifier and inverter sides have been modeled as $\mathrm{AC}$ grid equivalents with equivalent Thevenin impedances of $Z_{\text {sys }}$ and $Z_{\text {si }}$ respectively (as shown in Fig. 5). Accordingly, the system strength of the parallel AC network on the rectifier side can be determined based on $Z_{\text {sys }}$, which is inversely proportional to the short circuit ratio (SCR). In the simulation study, $Z_{\text {sys }}$ is assumed to be very high so as to depict the worse case scenario, where the electrical damping of the interconnected AC-DC system is contributed solely by the HVDC system. In this paper, the AC system with short circuit ratios (SCRs) of $2.5 \angle 84^{\circ}$ and $10 \angle 75^{\circ}$ is considered to represent the weak and strong system respectively [24].

\section{Simulation Results}

The interaction behavior of an HVDC system with a nearby generator is investigated through sensitivity analysis. It identifies the system parameters at different operating conditions, that may result in instability or pose negative damping.

Extensive simulation studies have been conducted to examine the amount of the electrical damping for the interconnected AC-DC system within the frequency range of interest. Different scenarios as highlighted below have been investigated:

- Hydroelectric unit with different power output capacities $\left(S_{\text {hydro }}\right)$,

- Hydroelectric unit with different loading levels $\left(P_{h y d r o}\right)$,

- Varying power flows through a DC link $\left(P_{d c}\right)$,

- Different levels of AC system strength $\left(Z_{s y s}\right)$, and

- Different current controller gains.

The following subsections demonstrate the perturbation analysis as a screening tool to investigate the effect of negative damping, contributed inherently by the current controller operation at the HVDC rectifier station, on hydroelectric turbinegenerator units. It is assumed that the firing angle at the rectifier station varies between 15 to 20 degrees.

\section{A. Perturbation analysis from machine side (mechanical sys- tem perturbation)}

A PSCAD ${ }^{\circledR} /$ EMTDC $^{\complement}$ simulated model is used for damping torque analysis as described in Section IV. A small sinusoidal perturbation of rotor speed $\left(\Delta \omega_{r}\right)$ of $0.01 \sin \left(\omega_{m} t\right)$ is introduced on the synchronous machine by disabling the rotor dynamics. The resulted electromagnetic torque deviation $\left(\Delta T_{e}\right)$ is measured and the magnitude and phase angle of electrical damping $\left(D_{e}\right)$ are also calculated for the frequency range of interest. The system stability can be determined from the electrical damping and phase angle plots. Torsional interactions between the hydroelectric unit and HVDC system are investigated through sensitivity analysis at different operating conditions for $0 \mathrm{~Hz} \leq f_{m} \leq 50 \mathrm{~Hz}$.

Fig. 8(a) shows the time response of the generator internal bus voltage resulting from a modulated frequency $\left(f_{m}\right)$ of $10 \mathrm{~Hz}$. Frequency spectrum of the $\mathrm{AC}$ voltage as seen in Fig. 8(b) illustrates that fundamental $\left(f_{f u n d}\right)$, sub- $\left(f_{s u b}\right)$ and super- $\left(f_{\text {super }}\right)$ synchronous frequency components exist when the rotor speed is modulated at $10 \mathrm{~Hz}$, with extra frequency components possibly arising as a result of multiple armature reaction. 


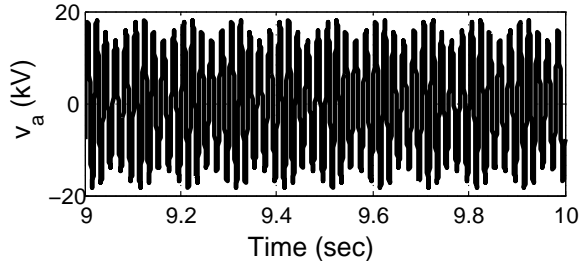

(a)

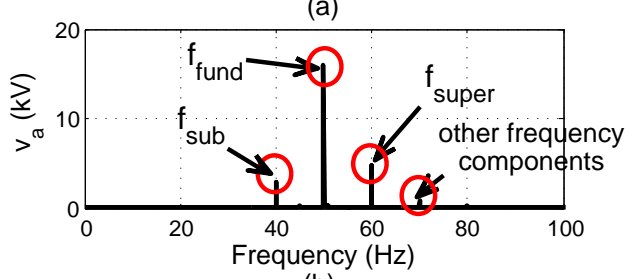

(b)

Fig. 8. (a) Time response and (b) frequency spectrum of AC voltage at a modulated frequency, $f_{m}$ of $10 \mathrm{~Hz}$.

1) Hydroelectric unit with different power output capacities: The electrical damping plots for a hydroelectric turbinegenerator (TG) unit connected in parallel with a weak AC network (SCR of $2.5 \angle 84^{\circ}$ ), and with the rated DC power transfer, are shown in Fig. 9(a). It is assumed that the hydroelectric unit operates at 0.85 power factor lagging. It is observed that the negative damping exists for a frequency range of $4 \mathrm{~Hz} \leq f_{m} \leq$ $9 \mathrm{~Hz}$. The torsional frequency of a hydroelectric TG unit falls well within the frequency range where the negative damping persists. This suggests that the current controller of the rectifier can possibly destabilize the torsional interaction. However, if the mechanical damping exceeds the electrical damping in magnitude, the system could be stable. Modal analysis will be elaborated later to further evaluate the possible SSTI behavior of the hydroelectric unit with an HVDC system.

The system electrical damping for a hydroelectric TG unit connected in parallel with a strong AC network (SCR of $10 \angle 75^{\circ}$ ), with the rated DC power transfer and the rated generator loading, is greatly enhanced as shown in Fig. 9(b). A much higher amount of positive electrical damping is provided for most of the frequency range of interest. Thus, SSTI is highly unlikely to be observed on any hydroelectric unit when a strong $\mathrm{AC}$ network is connected in parallel to the rectifier station.

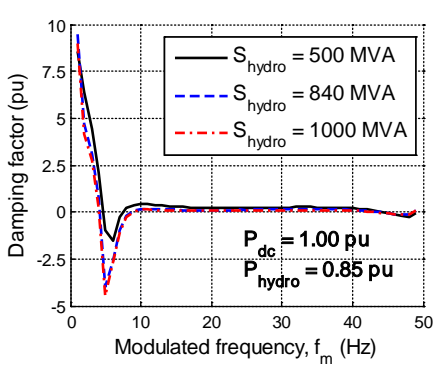

(a)

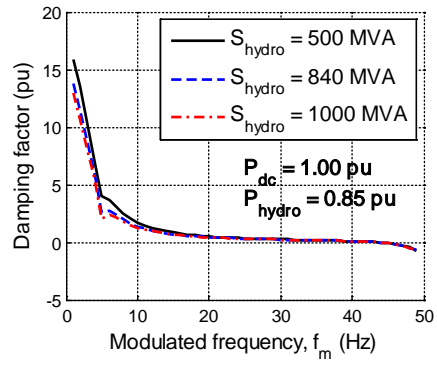

(b)
Fig. 9. Electrical damping for a hydroelectric turbine-generator unit with (a) a weak AC link in parallel (b) a strong AC link in parallel

2) Hydroelectric unit with different loading $\left(P_{\text {hydro }}\right)$ : Hydroelectric units operating at different loading levels, i.e. $P_{\text {hydro }}=0.75 \mathrm{pu}, 0.5 \mathrm{pu}$ and $0.25 \mathrm{pu}$, are investigated. Figs. 10 (a), (b) and (c) highlight the electrical damping contribution for hydroelectric units with different capacities and loadings, connected in parallel with a weak AC system interconnected to the HVDC system. It is shown in Fig. 10(c) that the hydroelectric unit of 1000 MVA experiences electrical damping of $-4.5 \mathrm{pu}$ for $0.85 \mathrm{pu}$ loading. Similarly, electrical damping contribution from the network increases to -1.5 pu for 0.25 pu loading.

Negative electrical damping contributions for hydroelectric units of 500 MVA and 840 MVA are observed in Fig. 10(a) and (b) respectively. The hydroelectric units of 840 MVA and 500 MVA experience electrical damping of -4 pu and -1.5 pu for 0.85 pu loading under normal operation.

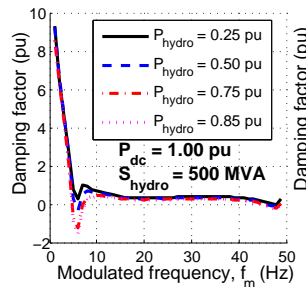

(a)

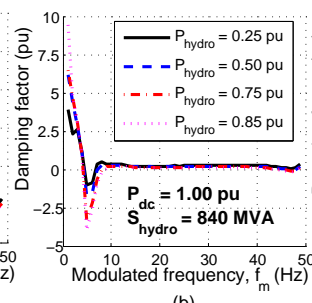

(b)

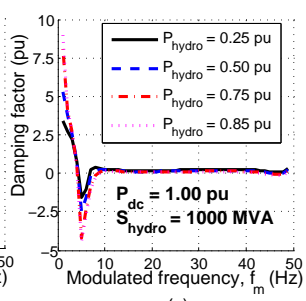

(c)
Fig. 10. Electrical damping for a hydroelectric turbine-generator unit with a weak parallel AC network connection and different generator loadings, $P_{\text {hydro }}$ and capacities, $S_{\text {hydro }}$

3) DC line operating at different power flow $\left(P_{d c}\right)$ : Simulation results presented in Figs. 11(a), (b) and (c) show that the system is more susceptible in imposing negative damping when the DC line is operating at a higher level of power flow. In fact, positive damping has been provided for the frequency range of interest when the DC power flow $\left(P_{d c}\right)$ is $0.5 \mathrm{pu}$ and $0.25 \mathrm{pu}$ for all hydroelectric units of different capacity and loading. It can be summarized that for a hydroelectric unit connected in parallel with a weak AC system integrated to the HVDC system, the overall contribution of the electrical damping increases with low DC power transfer.

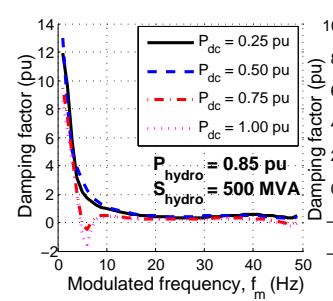

(a)

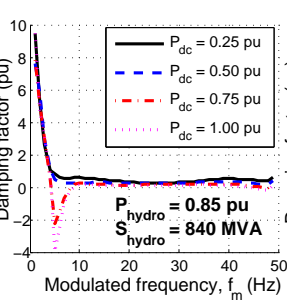

(b)

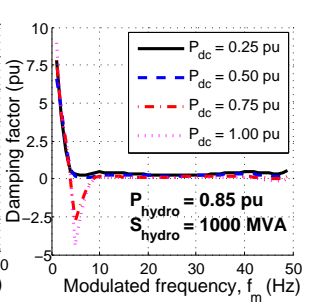

(c)
Fig. 11. Electrical damping for a hydroelectric turbine-generator unit with a weak parallel AC network connection and varying DC power flow

4) Sensitivity analysis of current controller gains on electrical damping: The torsional interactions between the generator unit and the HVDC system are highly sensitive to the current controller gains. The effect of the rectifier current controller gains $\left(K_{p}\right.$ and $\left.K_{i}\right)$ onto the electrical damping is examined. The sensitivity of the current controller integral gain $\left(K_{i}\right)$ on the electrical damping with proportional gain $\left(K_{p}\right)$ set to 1.0989 is demonstrated in Fig. 12(a), whereas Fig. 12(b) presents the sensitivity of the proportional gain $\left(K_{p}\right)$ on the electrical damping with $K_{i}$ set to 91.58 for $0<f_{m} \leq 50 \mathrm{~Hz}$. 


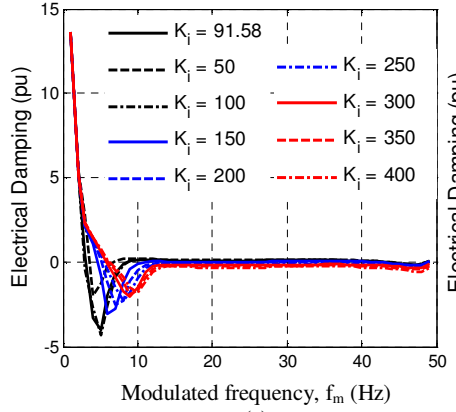

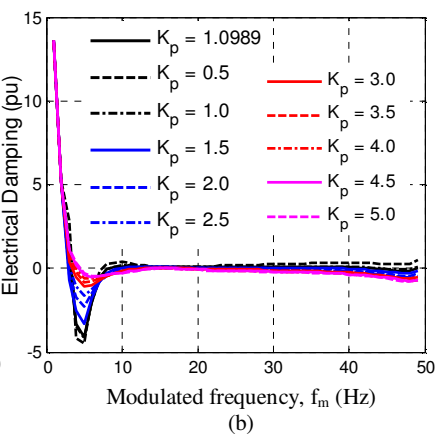

Fig. 12. Sensitivity analysis of current controller (a) $K_{i}$ and (b) $K_{p}$ gains on electrical damping

It is observed that the frequency range in which the negative damping persists varies with the change in $K_{i}$ as shown in Fig. 12(a). The effect of $K_{i}$ on the damping contribution is predominant when the torsional mode of $6.3 \mathrm{~Hz}$ is selected for the study as seen in Fig. 13(a) with a fixed value of $K_{p}$. It is observed in Fig. 12(b) that the negative damping exists for a frequency range of $4 \mathrm{~Hz} \leq f_{m} \leq 9 \mathrm{~Hz}$ for most of the $K_{p}$ values with $K_{i}$ set to 91.58 . The torsional mode of a hydro unit falls well within the frequency range where the negative damping persists. The decrease in $K_{p}$ results in a large contribution of negative damping.

The dependency of $K_{i}$ and $K_{p}$ on the electrical damping for the torsional mode $\left(f_{n}\right)$ of $6.3 \mathrm{~Hz}$ can be evidenced in Figs. 13(a) and (b). Fig. 13(a) shows the electrical damping as a function of $K_{i}$ for different values of $K_{p}$. The torsional mode experiences the least damping when $K_{i}$ is 150 . The electrical damping can be improved by increasing $K_{p}$.

The electrical damping presented as a function of $K_{p}$ for different values of $K_{i}$ is demonstrated in Fig. 13(b). As seen in the figure, the electrical damping contribution is consistent for $K_{p}$ variation with a high value of $K_{i}$. For a low value of $K_{i}$ (i.e. $K_{i}=50$ ), positive electrical damping is obtained for the torsional mode for low values of $K_{p}$ (i.e. $K_{p} \leq 1$ ). However, increase in $K_{p}$ results in a decrement in electrical damping, and the mode becomes unstable.

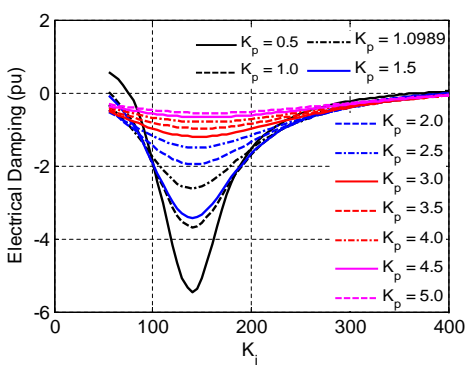

(a)

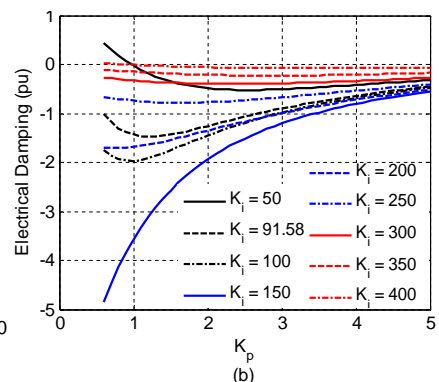

(b)
Fig. 13. Sensitivity analysis of current controller (a) $K_{i}$ and (b) $K_{p}$ gains on electrical damping for the torsional mode of hydro unit $f_{n}=6.3 \mathrm{~Hz}$

\section{B. Perturbation analysis from AC network side (electrical system perturbation)}

Voltage perturbation at different modulated frequency $\left(f_{m}\right)$ is applied at the terminal bus to depict the perturbation arising from HVDC system operation (network side perturbation). The perturbation is mathematically expressed in (15). The resulting deviation in the TG torque (mechanical torque) of the hydroelectric unit is then measured for different modulated frequencies. The TG torque signal is further passed through the bandpass filter so as to extract the frequency component of interest.

The torsional data for hydroelectric units presented in Table I is derived from [3] and is used for torsional interaction studies reported in this paper. Perturbation signal $\left(\Delta \omega_{r}\right)$ of 0.1 $\mathrm{pu}$ is applied so as to depict the severe faults at the generator terminal. Fig. 14 shows the resulting deviation in TG torque of the hydroelectric units, rated at 500 MVA, 840 MVA and 1000 MVA with different shaft parameters (as given in Table I), for $0 \mathrm{~Hz} \leq f_{m} \leq 12 \mathrm{~Hz}$. As seen, TG torque oscillations can be excited at torsional frequency of the mechanical shaft.

TABLE I

HYDROELECTRIC TORSIONAL SHAFT SYSTEM DATA

\begin{tabular}{|c|c|c|c|}
\hline Shaft & 1 & 2 & 3 \\
\hline Speed (rpm) & 136.4 & 100 & 115.4 \\
$H_{\text {gen }}(\mathrm{s})$ & 4.54 & 2.16 & 2.29 \\
$H_{\text {tur }}(\mathrm{s})$ & 0.22 & 0.26 & 0.22 \\
GTI & 20.5 & 8.2 & 10.6 \\
$f_{n}(\mathrm{~Hz})$ & 8.6 & 6.3 & 7.2 \\
\hline
\end{tabular}

The three shaft systems under investigation have the torsional frequencies $\left(f_{n}\right)$ of $8.6,6.3$ and $7.2 \mathrm{~Hz}$. These torsional frequencies fall between $4-9 \mathrm{~Hz}$, where the electrical damping contribution from the system is negative as discussed in the previous Section. TG torque deviations are found to be $1.0 \mathrm{pu}$, $1.5 \mathrm{pu}$ and $0.6 \mathrm{pu}$ for a $500 \mathrm{MVA}$ hydroelectric unit with shaft system 1, 2 and 3 respectively. For hydroelectric units rated at 840 MVA and 1000 MVA, the resulting TG torque deviations are less than $0.5 \mathrm{pu}$ for all shaft systems under consideration.
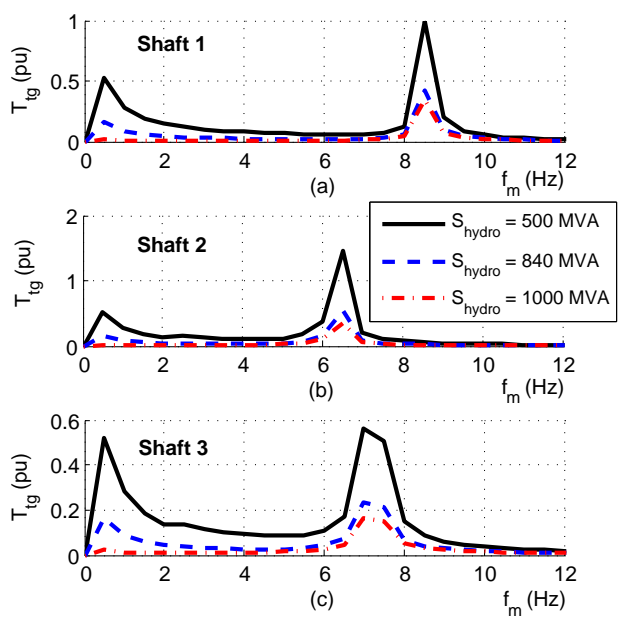

Fig. 14. Turbine-generator torque vs modulated frequency

This screening analysis demonstrates that TG torque can be excited at the torsional frequency on a hydroelectric unit. It is vital to carry out further investigations especially using time domain simulations.

\section{Time Domain Analysis}

Subsections VI-A and VI-B have presented the perturbation analysis for investigating the potential SSTI phenomenon. This subsection further examines the SSTI behavior of hydroelectric 
units with different shaft systems (as given in Table I), for a sample network depicted in Fig. 5, through time domain simulation studies conducted using PSCAD $^{\circledR} /$ EMTDC $^{\complement}$. Hydroelectric units rated at 500 MVA, 840 MVA and 1000 MVA are considered for the investigation. It is assumed that the hydroelectric unit and DC line are operating at rated condition, i.e. $P_{\text {hydro }}=0.85 \mathrm{pu}$ and $P_{d c}=1.0 \mathrm{pu}$. Moreover, the firing angle $(\alpha)$ varies between $15^{\circ}$ and $20^{\circ}$.

1) Three-phase to ground fault at the rectifier station: As per IEEE Std C50.12-2005, the initial steady-state voltage at the generator bus is set to be at 1.05 pu before applying electrical perturbation. A three-phase to ground fault is applied at the rectifier station at $t=0.5 \mathrm{sec}$, and is cleared in 3 cycles, i.e. $0.06 \mathrm{sec}$ for a $50 \mathrm{~Hz}$ system. A three-phase to ground fault at the rectifier station is considered as worst case scenario, and will have greater impact on the generator unit due to the electrically-close distance between the unit and the rectifier station.

This disturbance was noted to induce small voltage fluctuations between the frequency range of $35 \mathrm{~Hz} \leq f \leq 65$ Hz. There are still other frequency components present in the voltage fluctuations, but they are of relatively small magnitude. The mechanical torsional mode frequency $\left(f_{n}\right)$ falls wellwithin the complement of the system resonance frequency range $\left(f_{m}=f_{b}-f_{\text {sub }}\right.$ or $\left.f_{\text {super }}-f_{b}\right)$. This complement frequency range is between $0 \mathrm{~Hz} \leq f_{m} \leq 15 \mathrm{~Hz}$.

Figs. 15, 16 and 17 show the TG torque for hydroelectric units with capacities of 500 MVA, 840 MVA and 1000 MVA associated with shaft system 1, 2 and 3 respectively for a three-phase to ground fault at the rectifier station. The total simulation time of $150 \mathrm{sec}$ is considered. Insets have been included in the figures to demonstrate the oscillation frequency of the response for the snapshot of $0.4 \mathrm{sec}$. It is observed that the sustained TG torque oscillations are present due to the occurrence of the three-phase fault in most of the cases. However, the oscillating TG torque for the hydroelectric unit of 500 MVA (with shaft systems 2 and 3) eventually settles down, as seen in Figs. 15(b) and (c), while Figs. 16(b), 17(b) and $17(\mathrm{c})$ demonstrate the cases of growing oscillations in TG torque for the hydroelectric unit of 840 MVA capacity associated with shaft system 2, and 1000 MVA hydroelectric unit with shaft systems 2 and 3. It is seen in Fig. 17(a) that the oscillations grow slowly even with a high GTI ratio of 20.5 .

The corresponding frequency spectrums of the TG torque are shown in Fig. 18(i). These figures demonstrate the contribution from the torsional modes towards the TG torque oscillation, and also suggest that the TG torque deviation is the highest when the hydroelectric TG unit has the lowest GTI ratio. From the system studies, the second shaft system presented in Table I has the lowest GTI of 8.2, followed by the third shaft system with a ratio of 10.6 and lastly, the first shaft system having the GTI value of 20.5. The corresponding TG torque deviation for hydroelectric unit with first shaft system in service is the least (i.e. $<0.05 \mathrm{pu}$ ). It is also observed that the TG torque deviation is higher when a hydroelectric unit of higher capacity is in operation. As shown in Fig. 18(ii), it is noted that the torsional modes of hydroelectric units with shaft systems under investigation have very little contribution to the rotor speed deviation $\Delta \omega_{r}$. It is noted that $\Delta \omega_{r}$ is less than $0.35 \mathrm{rad} / \mathrm{sec}$ for hydroelectric unit associated with shaft system 2 while $\Delta \omega_{r}$ is less than $0.04 \mathrm{rad} / \mathrm{sec}$ for hydroelectric unit with shaft system 1 .

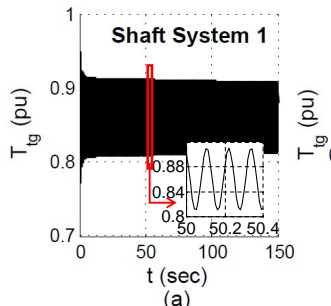

(a) (b)

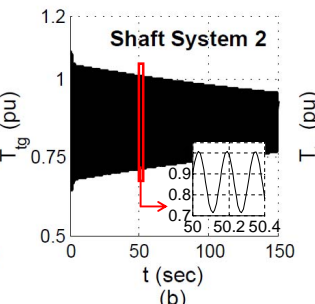

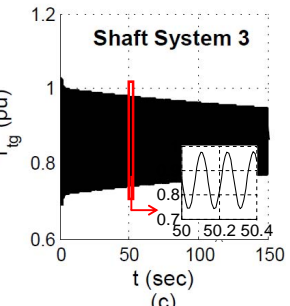

Fig. 15. TG torque response of 500 MVA hydro unit for three-phase to ground fault at the rectifier station

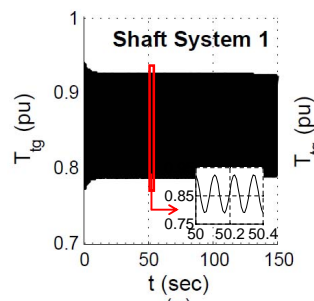

(a)

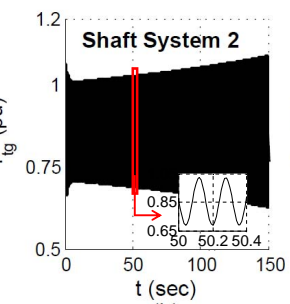

(b)

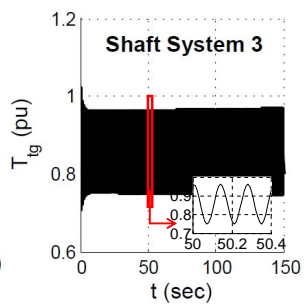

(c)
Fig. 16. TG torque response of 840 MVA hydro unit for three-phase to ground fault at the rectifier station

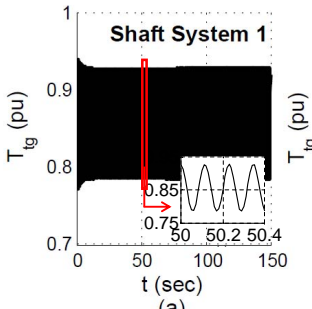

(a)

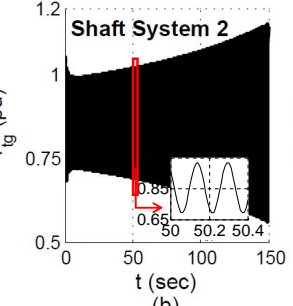

(b)

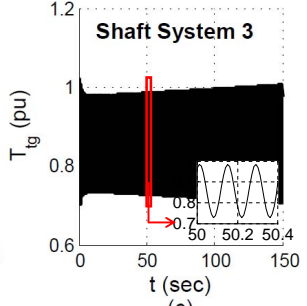

(c)
Fig. 17. TG torque response of 1000 MVA hydro unit for three-phase to ground fault at the rectifier station

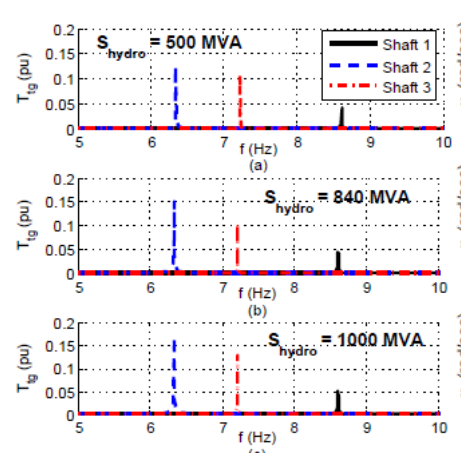

(i)

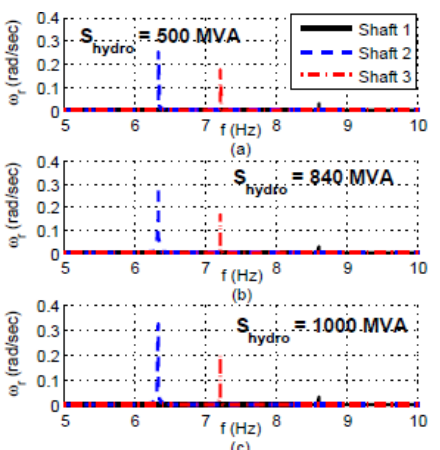

(ii)
Fig. 18. Frequency spectrum of (i) TG torque (ii) rotor speed of hydroelectric unit for a three-phase to ground fault at the rectifier station

Figs. $19-21$ illustrate the time responses of the rotor speed oscillations for hydroelectric units of capacities $\left(S_{\text {hydro }}\right) 500$ MVA, 840 MVA and 1000 MVA associated with shaft system 1,2 and 3 . The rotor speed oscillation eventually damps down for most cases as shown in Figs. 19 - 21, however, there are cases where the rotor speed oscillation grows, leading to the system instability as seen in Figs. 20(b), 21(b) and 21(c). 

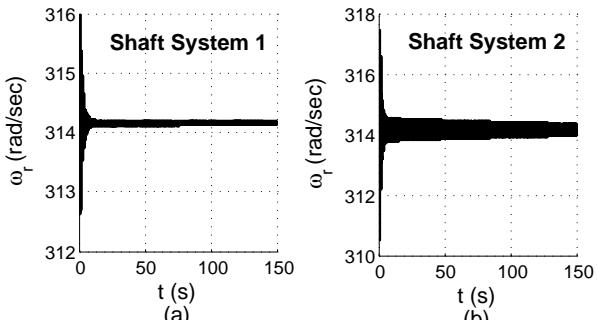

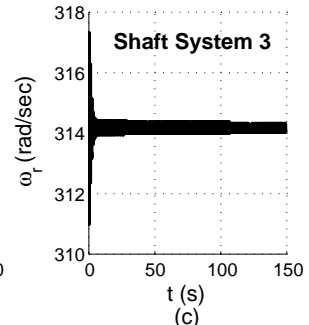

Fig. 19. Rotor speed response of 500 MVA hydro unit for three-phase to ground fault at the rectifier station

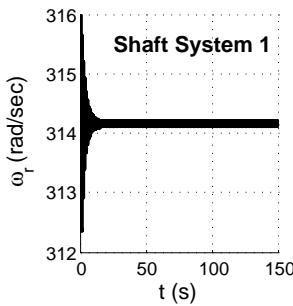

(a)

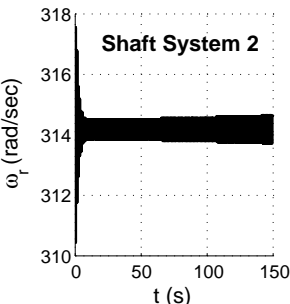

(b)

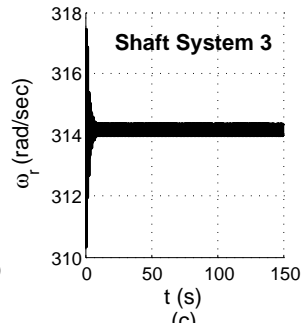

Fig. 20. Rotor speed response of 840 MVA hydro unit for three-phase to ground fault at the rectifier station

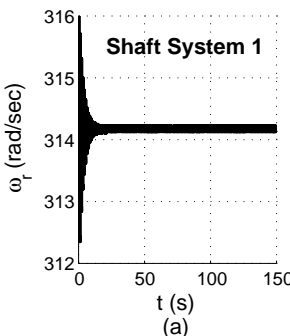

(a)

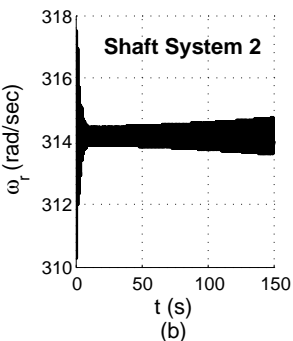

(b)

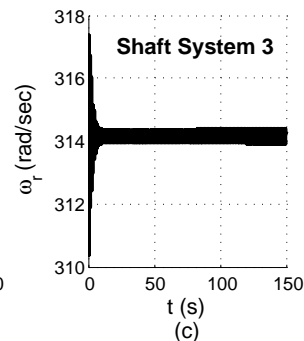

(c)

Fig. 21. Rotor speed response of 1000 MVA hydro unit for three-phase to ground fault at the rectifier station

2) Step change applied on the current controller: SSTI is generally resulted from the interaction of a TG unit with fast acting controllers of power system components. The hydro unit's responses are observed with a step change applied on the current controller. Similar results as that subjected to a threephase to ground fault are obtained. The TG torque responses of 500 MVA, 840 MVA and 1000 MVA hydro units for a step change on the current controller are shown in Figs. 22,23 and 24 respectively. Insets have been included in the figures to demonstrate the oscillation frequency of the response for the snapshot of $0.4 \mathrm{sec}$. The corresponding rotor speed responses of the hydroelectric units are given in Figs. 25, 26 and 27. Growing TG torque oscillations are expected for the hydro units with higher capacities (840 MVA and 1000 MVA) associated with shaft systems 2 and 3, which have low GTI ratios of 8.2 and 10.6 respectively. These are evidenced in Figs. 23(b), 23(c), 24(b) and 24(c).

The decrement factor of the integrated hydroelectric unit and an HVDC system is demonstrated in Fig. 28 as a function of GTI ratio and turbine damping ( $D_{\text {tur }}$ ) for turbine-generator damping $\left(D_{t g}\right)$ between $0 \mathrm{pu}$ and $1.0 \mathrm{pu}$. The generator inertia $\left(H_{g e n}\right)$ of $2.158 \mathrm{sec}$ is considered. The worst electrical damping factor of $-4.5 \mathrm{pu}$ has been taken into account in order to obtain the respective modal damping, decrement factor and logarithmic decrement of the integrated AC-DC system.

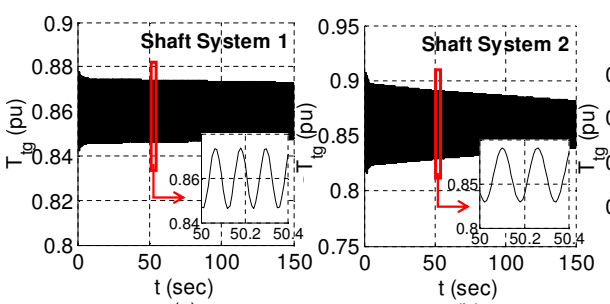

(a)

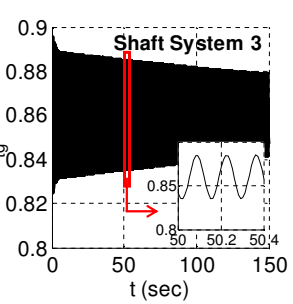

(c)
Fig. 22. TG torque response of 500 MVA hydro unit for a step change applied on the current controller

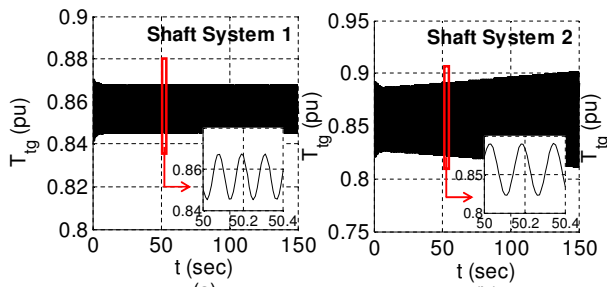

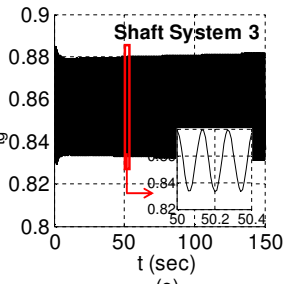

Fig. 23. TG torque response of 840 MVA hydro unit for a step change applied on the current controller

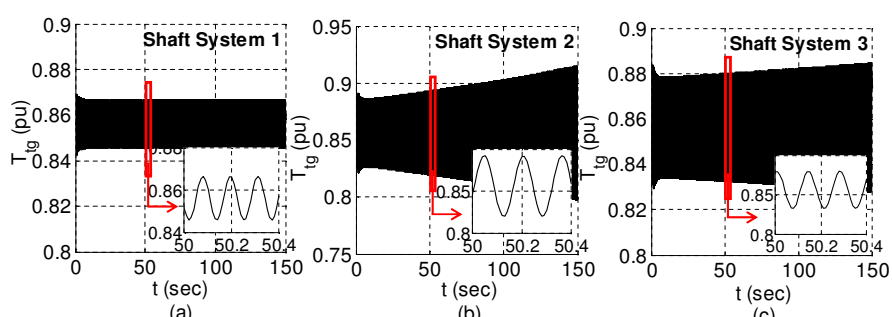

(a)

Fig. 24. TG torque response of 1000 MVA hydro unit for a step change applied on the current controller

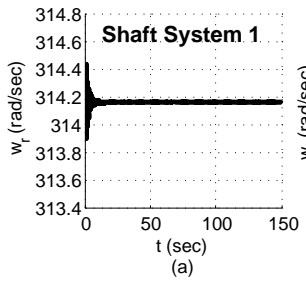

(a)

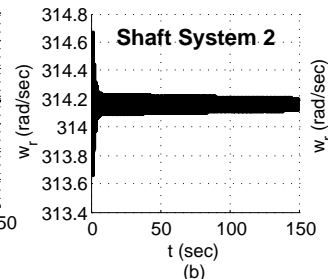

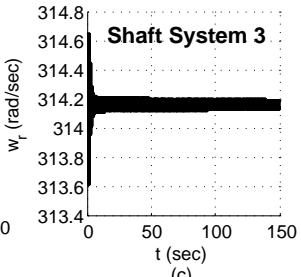

Fig. 25. Rotor speed response of 500 MVA hydro unit for a step change applied on the current controller
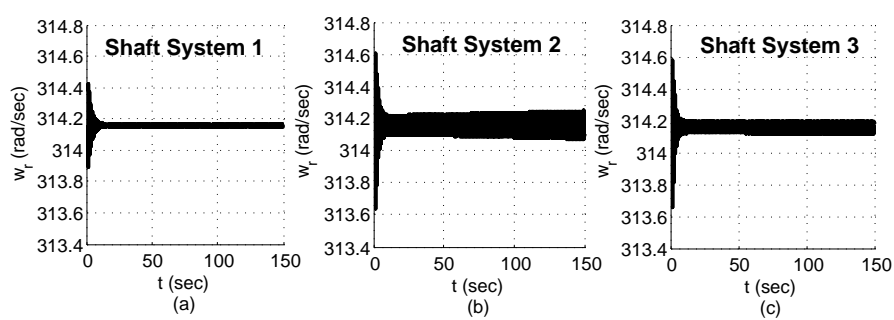

(c)

Fig. 26. Rotor speed response of 840 MVA hydro unit for a step change applied on the current controller

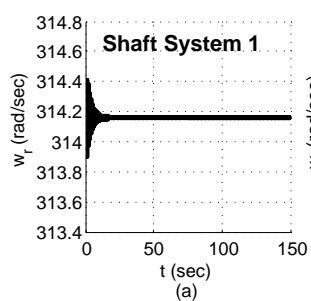

(a)

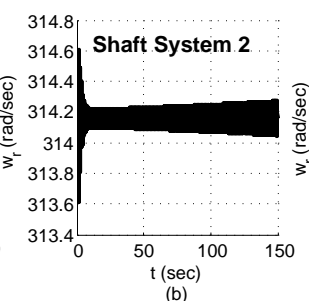

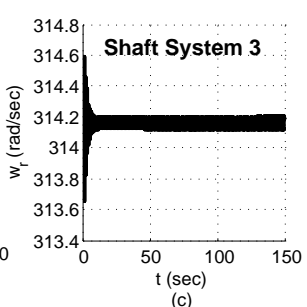

Fig. 27. Rotor speed response of 1000 MVA hydro unit for a step change applied on the current controller 
It is observed in Fig. 28 that the decrement factor of the integrated system becomes negative for a low GTI ratio of hydroelectric TG unit when $D_{t g}=1.0 \mathrm{pu}$. This may result in sustained or growing subsynchronous oscillations. Fig. 29 presents the side view of the system decrement factor, with a clearer view shown in the inset. The decrement factor becomes negative when GTI $<1$ as seen in Fig. 29. If $D_{t g}$ is negligible $\left(D_{t g} \approx 0 \mathrm{pu}\right.$ ), there may be a system, with different combination of GTI ratio and $D_{\text {tur }}$, experiencing SSTI. This is shown in Fig. 28, as indicated by a stability boundary of $\sigma_{m}=0$. For a system with any combination of $D_{\text {tur }}$ and GTI that falls below the indicative stability boundary, the system experiences unstable SSTI phenomenon.

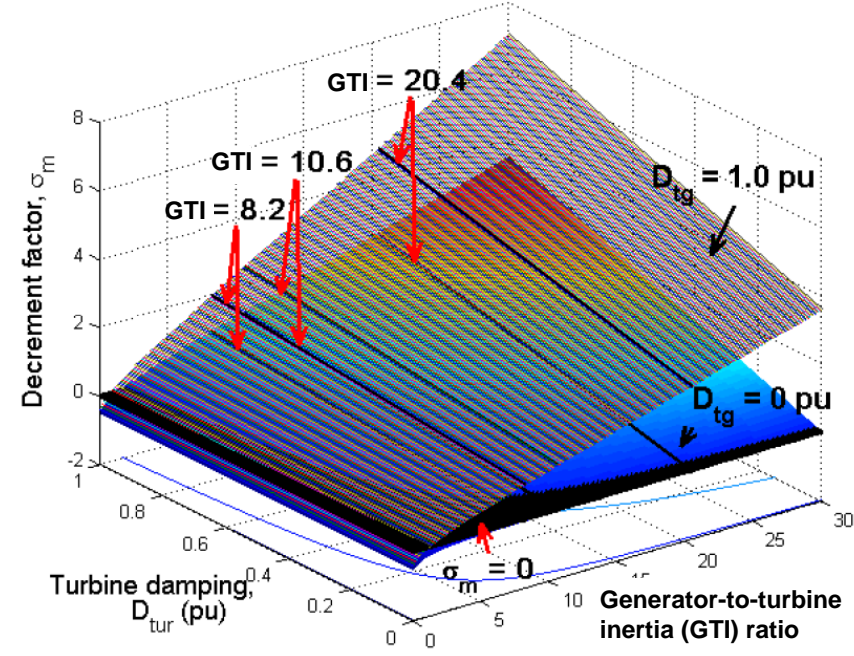

Fig. 28. Decrement factor of the integrated hydroelectric unit and an HVDC system

As shown in Fig. 29, the negative system decrement factor is observed for all GTI values with $D_{t g}=0 \mathrm{pu}$, which suggests that the system may experience SSTI instability even when a hydroelectric unit with higher GTI ratio is in operation. The growing subsynchronous oscillations in TG torque, as seen in Figs. 17(b), 17(c), 24(b) and 24(c) for a 1000 MVA hydroelectric unit operating close to the HVDC system, are due to lack of modal damping in the system with a relatively low value of modal decrement factor.

3) Damping improvement by subsynchronous damping controller: Subsynchronous damping controller (SSDC), constituting a washout filter, a SSDC gain block and a leadlag phase compensator, as seen in Fig. 30 can be designed and incorporated to the current controller of the rectifier to overcome the torsional interaction between the TG unit and the HVDC system. The phase characteristics of SSDC can be designed properly to compensate any phase lead/lag between the current controller input and the generator electrical torque, so as to provide positive damping at the required frequency range [21], [25]. The frequency response between the constant current controller input and the generator electrical torque, to determine the phase compensation required, can be obtained with the assumption that the generator angle is maintained constant. A washout filter, which is a high pass filter, is also included to remove the steady speed variations [25].

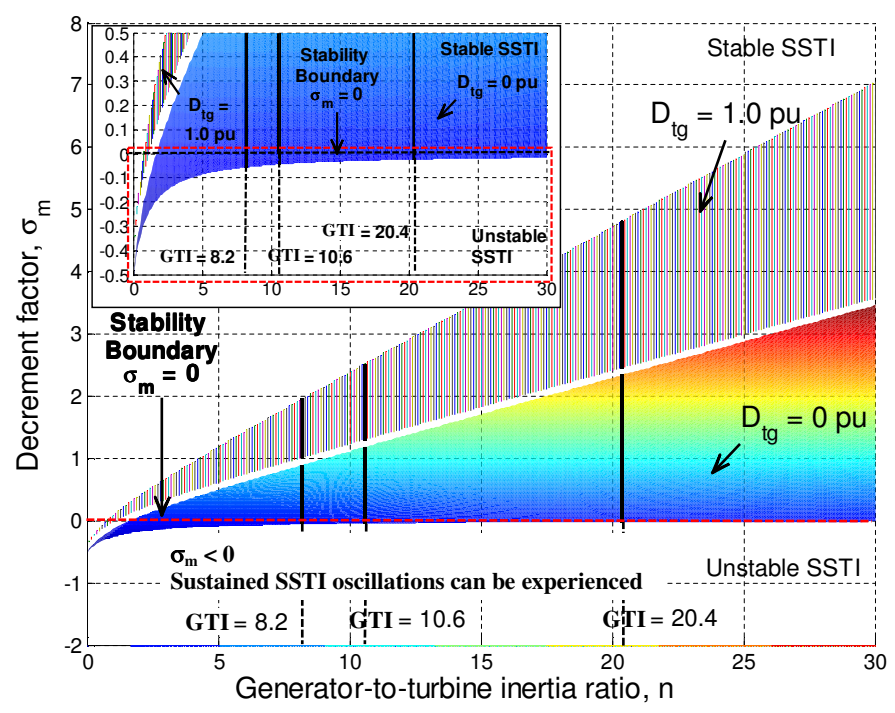

Fig. 29. Decrement factor with respect to generator-to-turbine inertia ratio for a hydro unit connected to HVDC

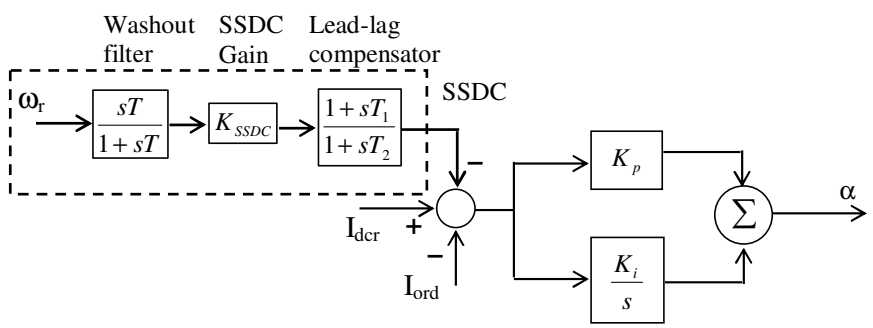

Fig. 30. Constant current controller with SSDC at rectifier station

It is noted that the torsional interactions between the HVDC controls and the hydro TG shaft system predominantly exist for the largest hydroelectric unit of 1000 MVA capacity with a small GTI ratio, where the turbine modal damping may not be sufficient to counteract the negative damping introduced by the HVDC current controller. Accordingly, a typical SSDC has been incorporated to demonstrate the mitigation of SSTI between the largest hydroelectric unit and the HVDC system at vulnerable torsional frequencies.

It is demonstrated that the TG torque deviation is critical for the largest hydro unit with the shaft system 2 (GTI ratio of 8.2). A typical SSDC is designed to improve the damping of the torsional mode for this machine. The improvement in TG torque response for a three-phase to ground fault at rectifier station when a SSDC is incorporated can be seen in Fig. 31(a). The corresponding rotor speed response is shown in Fig. 31(b). The system with no SSDC results in growing oscillations in TG torque and rotor speed responses as evidenced in Figs. 17(b) and 21(b) respectively. With the incorporation of a SSDC into the system, it is observed that the TG torque oscillations have subsequently been damped out and the system remains stable. 
TG torque response of 1000MVA hydro unit

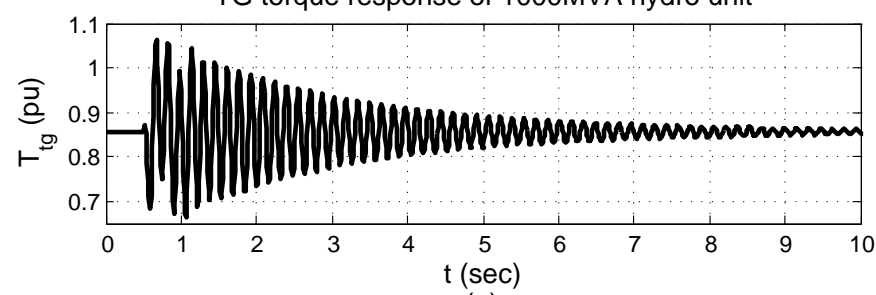

(a)

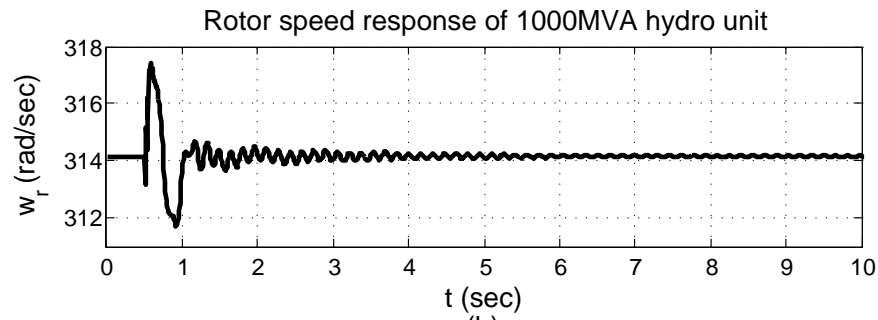

(b)

Fig. 31. (a) TG torque response and (b) rotor speed response of 1000MVA hydro unit for three-phase to ground fault at the rectifier station with SSDC incorporated in $\mathrm{CC}$ controller at rectifier

\section{CONCLUSION}

This paper has investigated subsynchronous torsional interaction (SSTI) for a hydroelectric turbine-generator unit connected to an HVDC system under different operating conditions. Damping torque analysis has been conducted to examine the SSTI. Sensitivity analysis has revealed that a system with a higher hydroelectric generator loading, higher DC power transfer or a weak AC link is more susceptible to SSTI instability. It is found that the torsional frequency of a hydroelectric TG unit may fall well-within the frequency range of the negative damping introduced by the HVDC current controller. The modal torsional damping may be sufficient to diminish the negative damping effect posed by the HVDC current controller with a relatively high value of generator-toturbine inertia ratio. It is also observed that the hydroelectric TG units may experience instability for large disturbances such as three-phase to ground fault at the rectifier station. Sustained and growing TG torque oscillations are noted for some operating conditions, for which the rotor speed oscillations may grow, resulting in system instability. SSTI phenomenon is predominant for an HVDC system integrated hydroelectric unit with low generator-to-turbine inertia ratio due to deficiency in modal damping.

\section{ACKNOWLEDGEMENT}

Authors would like to acknowledge the support provided by Garth Irwin, Electranix Corporation, in relation to the SSTI studies associated with turbine-generator units.

\section{REFERENCES}

[1] M. Bahrman, E. V. Larsen, R. J. Piwko, and H. S. Patel, "Experience with HVDC-turbine-generator torsional interaction at square butte," IEEE Trans. Power App. Syst., vol. PAS-99, no. 3, pp. 966 -975, May 1980.

[2] K. Clark, "Overview of subsynchronous resonance related phenomena," in 2012 IEEE PES Transmission and Distribution Conference and Exposition (T\&D), 2012, pp. 1-3.

[3] G. Andersson, R. Atmuri, R. Rosenqvist, and S. Torseng, "Influence of hydro units' generator-to-turbine inertia ratio on damping of subsynchronous oscillations," IEEE Trans. Power App. Syst., vol. PAS-103, no. 8 , pp. $2352-2361$, Aug. 1984.
[4] I. M. Canay, "A novel approach to the torsional interaction and electrical damping of the synchronous machine part i: Theory," IEEE Trans. Power App. Syst., vol. PAS-101, no. 10, Oct. 1982.

[5] - "A novel approach to the torsional interaction and electrical damping of the synchronous machine part ii: Application to an arbitrary network," IEEE Trans. Power App. Syst., vol. PAS-101, no. 10, Oct. 1982.

[6] L. Harnefors, "Analysis of subsynchronous torsional interaction with power electronic converters," IEEE Trans. Power Syst., vol. 22, no. 1, pp. $305-313$, Feb. 2007.

[7] _ "Proof and application of the positive-net-damping stability criterion," IEEE Trans. Power Syst., vol. 26, no. 1, pp. 481-482, Feb. 2011.

[8] C. Karawita and U. D. Annakkage, "Multi-infeed hvdc interaction studies using small-signal stability assessment," IEEE Trans. Power Del., vol. 24, no. 2, pp. $910-918$, Apr. 2009.

[9] N. Prabhu and K. R. Padiyar, "Investigation of subsynchronous resonance with vsc-based hvdc transmission systems," IEEE Trans. Power Del., vol. 24, no. 1, pp. 433 -440, Jan. 2009.

[10] A. Tabesh and R. Iravani, "Frequency-response analysis of torsional dynamics," IEEE Trans. Power Syst., vol. 19, no. 3, pp. 1430 - 1437, Aug. 2004.

[11] S. Dahal, N. Mithulananthan, and T. Saha, "Assessment and enhancement of small signal stability of a renewable-energy-based electricity distribution system," IEEE Trans. Sustain. Energy, vol. 3, no. 3, pp. 407 -415 , july 2012.

[12] M. Khan, M. Iqbal, and J. Quaicoe, "Effects of efficiency nonlinearity on the overall power extraction: A case study of hydrokinetic-energyconversion systems," IEEE Trans. Energy Convers., vol. 26, no. 3, pp. $911-922$, sept. 2011.

[13] —, "Dynamics of a vertical axis hydrokinetic energy conversion system with a rectifier coupled multi-pole permanent magnet generator,' IET Renewable Power Generation, vol. 4, no. 2, pp. 116 -127, march 2010.

[14] J. O'Reilly, A. Wood, and C. Osauskas, "Frequency domain based control design for an hvdc converter connected to a weak ac network," IEEE Trans. Power Del., vol. 18, no. 3, pp. 1028 - 1033, july 2003.

[15] J. Bladh, P. Sundqvist, and U. Lundin, "Torsional stability of hydropower units under influence of subsynchronous oscillations," IEEE Trans. Power Syst., vol. PP, no. 99, pp. 1-8, 2013.

[16] P. Kundur, Power System Stability and Control. McGraw-Hill, 1994.

[17] P. C. Krause, O. Wasynczuk, and S. D. Sudhoff, Analysis of Electric Machinery. The Institute of Electrical and Electronics Engineers, Inc., New York, 1995

[18] K. R. Padiyar, Analysis of Subsynchronous Resonance in Power Systems. Kluwer Academic Publishers, 1999.

[19] "Torsional interaction between electrical network phenomena and turbine-generator shafts: plant vulnerability," EPRI, Tech. Rep., Nov. 2006.

[20] "Proposed terms and definitions for subsynchronous oscillations," IEEE Trans. Power App. Syst., vol. PAS-99, no. 2, pp. 506 -511, Mar. 1980.

[21] D.-J. Kim, H.-K. Nam, and Y.-H. Moon, "A practical approach to hvdc system control for damping subsynchronous oscillation using the novel eigenvalue analysis program," IEEE Trans. Power Syst., vol. 22, no. 4, pp. $1926-1934$, Nov. 2007.

[22] P. Pourbeik, A. Bostrom, and B. Ray, "Modeling and application studies for a modern static var system installation," IEEE Trans. Power Del., vol. 21, no. 1, pp. 368 - 377, Jan. 2006.

[23] [Online]. Available: http://www.hydroconsult.de/content.php?action= forum

[24] M. Szechtman, T. Wess, and C. V. Thio, "First benchmark model for HVDC control studies," Electra, no. 135, pp. 54-73, Apr. 1991.

[25] C. Karawita and U. D. Annakkage, "Hvdc-generator-turbine torsional interaction studies using a linearized model with dynamic network representation," in International Conference on Power Systems Transients (IPST2009), 2009. 


\section{BIOGRAPHIES}

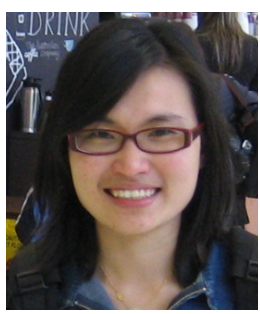

Yin Chin Choo was born in Malaysia in 1983. She received her B.E. (Hons.) degree from the University of Tasmania, Australia, in 2005. She is currently working with TransGrid, Sydney, Australia and pursuing the Ph.D. degree part-time at the University of Wollongong, Wollongong, Australia. Her research interests are power system analysis, hydroelectric turbine-generator, power system stability and power system planning, operation and control.

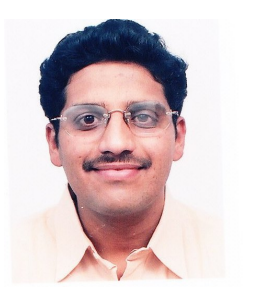

A. P. Agalgaonkar (M'09-SM'13) received the B.E. (Electrical Engineering) and M.E. (Electrical Power System) degrees from Walchand College of Engineering, Sangli, India, in 1997 and 2002, respectively, and the Ph.D. degree in Energy Systems Engineering from the Indian Institute of TechnologyBombay, Mumbai, India, in 2006.

$\mathrm{He}$ was a Scientist at the Energy Technology Centre, NTPC Ltd., Greater Noida, India, from 2005 to 2007 and was associated with the University of Tasmania, Hobart, Australia as a Postdoctoral Research Fellow from October 2007 to January 2008. In February 2008, he took up a position with the University of Wollongong, in Wollongong, Australia, as a Postdoctoral Research Fellow. Currently, he is a Lecturer at the University of Wollongong. His research interests include planning and operational aspects of renewable and distributed generation, microgrids, electricity markets and system stability.

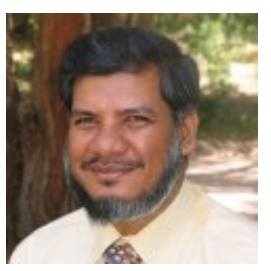

K. M. Muttaqi (M'01, SM'05) received the Ph.D degree from Multimedia University, Malaysia, in 2001. Currently, he is an Associate Professor at the School of Electrical, Computer, and Telecommunications Engineering, University of Wollongong, Wollongong, Australia. He was associated with the University of Tasmania, Australia as a Research Fellow/Lecturer/Senior Lecturer from 2002 to 2007, and with the Queensland University of Technology, Australia as a Research Fellow from 2000 to 2002. Previously, he also worked for Multimedia University as a Lecturer for three years. His research interests include distributed generation, renewable energy, power system planning and control.

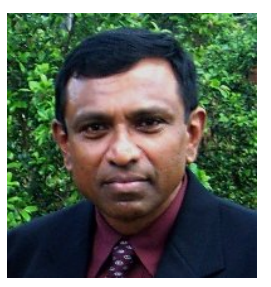

S. Perera (SM13) received the B.Sc. (Eng.) degree in electrical power engineering from the University of Moratuwa, Sri Lanka, the M.Eng.Sc. degree in electrical engineering from the University of New South Wales, Australia, in 1978, and the Ph.D. degree in electrical engineering from the University of Wollongong, Wollongong, Australia, in 1988. He has been a Lecturer at the University of Moratuwa, Sri Lanka. Currently, he is an Associate Professor with the University of Wollongong, where he is Quality and Reliability Centre. also the Technical Director of the Australian Power

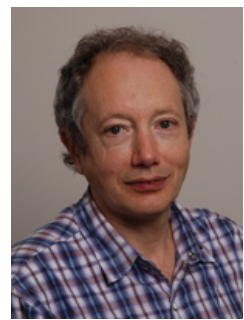

Michael Negnevitsky (M'95-SM'07) received the B.S.E.E. (Hons.) and Ph.D. degrees from the Byelorussian University of Technology, Minsk, Belarus, in 1978 and 1983, respectively. Currently, he is Chair Professor in Power Engineering and Computational Intelligence, the University of Tasmania, Australia. From 1984 to 1991, he was a Senior Research Fellow and Senior Lecturer in the Department of Electrical Engineering, Byelorussian University of Technology. After arriving in Australia, he was with Monash University, Melbourne, Australia. His interests are power system analysis, power quality, and intelligent systems applications in power systems. He is a Chartered Professional Engineer, Fellow of the Institution of Engineers Australia, and Member of CIGRE AP C4 (System Technical Performance), Member of CIGRE AP C6 (Distribution Systems and Dispersed Generation), Australian Technical Committee, and Member of CIGRE Working Group JWG C1/C2/C6.18 (Coping with Limits for Very High Penetrations of Renewable Energy), International Technical Committee. 